\title{
Common approach for supervising the railway safety performance
}

\author{
E. M. El Koursi ${ }^{1} \&$ L. Tordai ${ }^{2}$ \\ ${ }^{I}$ INRETS-ESTAS, Villeneuve d'Ascq, France \\ ${ }^{2}$ UIC, France
}

\begin{abstract}
The key aspect of maintaining and improving safety where possible is to supervise the safety targets at European and national levels. The railway safety directive is aiming to set Common Safety targets (CSTs) that must be reached by the different parts of the rail system and the system as a whole, expressed in risk acceptance criteria. This paper intends to summarise the main results of SAMNET "Safety Management and interoperability thematic network for railway systems" project. SAMNET belongs to the Fifth Framework Programme of the European Commission and addresses the Safety Directives issues. It focuses on the development of Common Safety Targets (CSTs) that are used for supervising the safety performance. The Common Safety Indicators (CSIs) that are used to ensure the measured safety performances (e.g. the effectiveness of Safety Management System) are discussed. The Common Safety Methods (CSMs) to ensure that the targets are correctly assigned and followed at all levels (company, state, Europe) are presented.
\end{abstract}

\section{Introduction}

The European Community regards its railways as an economic, efficient, environmentally friendly and very safe mode of transport. The railways need a liberalised rail transport market similar to those in the civil aviation and maritime sectors. The process of creating an internal European rail market has just started. The first railway package of European Directives creates a common framework for access to railway infrastructure and for allocation of railway infrastructure capacity. The European Directives on interoperability concern the global approach to all rail transport aspects, the second railway package, published in 
2004 (Directive [9] and [10]) expanded this approach by adding the safety aspects.

\section{SAMNET project}

SAMNET "SAfety Management and interoperability thematic NETwork for railways system" (El Koursi and Tordai [7]) is a project launched by the European Commission in 2003 to investigate and to propose the approaches to specify and to implement the requirements identified in the Safety Directives. In particular, issues concerning policies on Safety Management System, Common Safety Indicators, Common Safety Targets and Common Safety Methods are addressed by this project. The main results of the SAMNET project that ended its activities on December 2005 are summarised in the document referenced SAMNET synthesis report (El Koursi et al. [5]).

\section{Common tools to supervise the European railway safety}

For the creation of a single European rail transport market, it is important to increase confidence between the actors on the market and between member states. For this purpose the EU Safety Directive introduces a mechanism to adopt a minimum CST (common safety targets) expressed in risk acceptance criteria for individuals and for society. Member States shall ensure that railway safety is generally maintained and, where reasonably practicable, continuously improved, taking into consideration the development of Community legislation and technical and scientific progress and giving priority to the prevention of serious accidents.

\subsection{CST (Common Safety Targets)}

According to article 7.4 of the Safety Directive (Directive [8]), CSTs shall define the safety levels that must at least be reached by different parts of the railway system (such as conventional rail system, high speed rail system, long railway tunnels or lines solely used for freight transport) and by the system as a whole in each Member Sate, expressed in risk acceptance criteria for:

\section{a/ Individual risks relating to:}

- $\quad$ Passengers

- Staff including the staff of contractors

- Level crossing users and others,

- And, without prejudice existing national and international liability rules, individual risks relating to unauthorised persons on railway premises

\section{b/ Societal risks}

The CSTs (Cassir et al. [3] and EL Koursi et al. [5] can refer to different "groups at risk" such as passengers, staff, track workers etc. Besides these groups a distinction can be made between individual risk and collective or societal risk. Individual risk defines the chance of a person dying due do to a certain activity. 
Societal risk deals with the consequences of a railway accident on the environment (in terms of harm and damage).

According to Art 7.4, the Directive requires at least five different Global Safety Targets that must be reached in each Member State. These correspond to:

- Global individual risk for passengers

- Global individual risk for staff

- Global individual risk for level crossing users and others

- Global individual risk for unauthorised persons on railway premises

\subsubsection{Global CSTs and Specific CSTs}

Commonality for targets could therefore be considered only as applicable to objects which are to the same in all of the Member States such as generic functions, sub-systems, operations or part thereof which are characteristic of all area of the European rail system. Safety targets applied to requirements in TSIs, sub systems or Interoperability Constituents are good examples of such Specific Common Safety Targets.

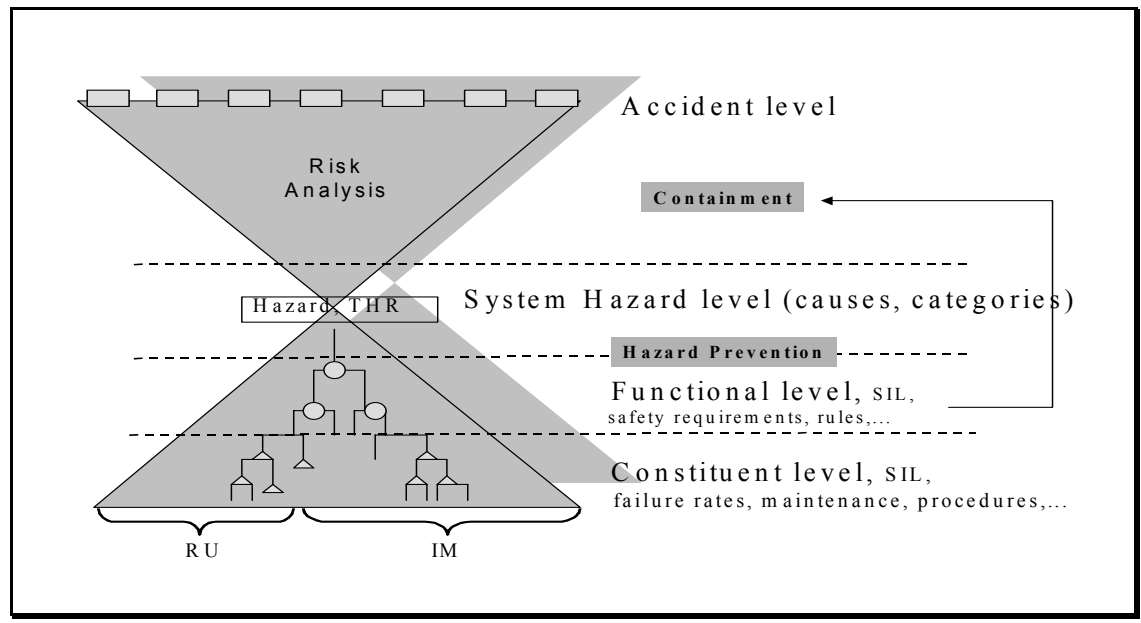

Figure 1: $\quad$ Proposed apportionment of safety targets.

Deriving acceptable risk levels for the various parts of the railway system requires first a classification of all the risks into various categories, and then the assignment of a target or acceptable risk level to each category with respect to each group(s) exposed to the risk. Such a process is also called risk apportionment. We can identify roughly 5 distinct approaches for the classification of risks (Mihm et al. [12]) and derivation of acceptable risk levels for parts of the railway system (Figure 1):

- $\quad$ System breakdown approach

- Breakdown by categories of hazard causes

- Functional breakdown approach

- Breakdown by hazard types 
- $\quad$ Breakdown by accident types

These 5 approaches ( 5 possible structures for Specific CSTs) correspond in fact to different levels of detail that can be focused on when analysing safety of a railway system. This can be illustrated by the following figure showing the hierarchy in a typical safety requirement allocation process (Cassir et al. [3]).

\subsubsection{Functional breakdown approach for CST apportionment}

The railway system is decomposed in six sub-systems that are: energy, infrastructure, control command and signalisation, rolling stock, operation and telematic. These subsystems are performed by a number of functions, which are implemented by a number of resources and programmes. All these elements constitute the Representative Architecture of the conventional rail system (Gigantino [11] and Chatel et al. [4]).

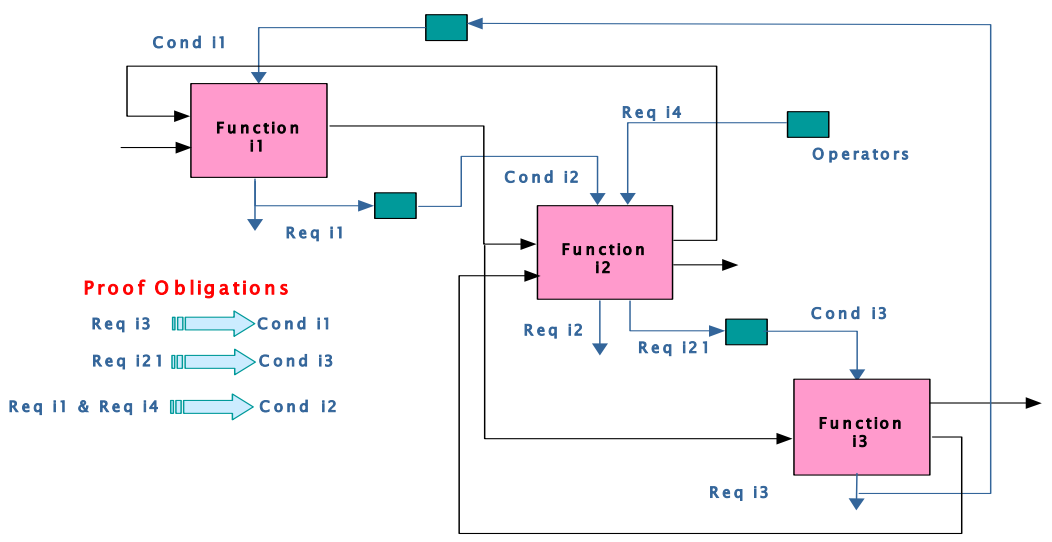

Figure 2: $\quad$ Proof obligations to validate the safety requirements.

This approach showed that if some functions can clearly be allocated to the IM or to the RU, responsibilities within other functions are shared. The shared responsibility aspect of some functions may derive from the goal of the function that involves both the IM and the RU or from the way it is implemented. Ensuring safe railway operations can also be expressed in a qualitative way. Both qualitative and quantitative safety targets can be allocated from a bottom-up approach as well as a top-down approach. The tool user is based on SADT technique associated with formal method based on proof obligations used to assess the allocated safety requirements (Figure 2). Global CSTs are the reference to derive CSTs for the various parts of the railway system because the specific acceptable risk levels should be derived for these different parts of the railway system as well as for the global safety targets.

We recommend the use of the AEIF [11] breakdown structure to manage the iceberg effect of setting targets at Member State level whilst we recognise that the AEIF functional breakdown is something that Member States have endorsed as a tool at Article 21 level. 


\subsection{CSI (Common Safety Indicators)}

\subsubsection{Relationship between CSTs and CSIs}

As the Safety Directive is aiming to set Common Safety Targets (CSTs) for monitoring safety performance, it is essential that an agreed set of Common Safety Indicators (CSIs) be used to ensure that measured safety performance (the effectiveness of Safety Management System) of different organisations are comparable and are related to CSTs (Tordai [13]). Each of these safety targets would need to be defined with adequate Common Safety Indicators (CSIs).

Table 1: $\quad$ Positions on Global safety targets and Indicators.

\begin{tabular}{|c|c|}
\hline $\begin{array}{l}\text { General Common } \\
\text { Safety Target }\end{array}$ & $\begin{array}{l}\text { General Common Safety Indicator (for one } \\
\text { Member State, per year) }\end{array}$ \\
\hline $\begin{array}{l}\text { Risk of death or serious } \\
\text { injury to passengers as } \\
\text { a result of train } \\
\text { operations or who are } \\
\text { harmed by any other } \\
\text { means }\end{array}$ & $\begin{array}{l}\text { Total number of deaths and of serious injuries on } \\
\text { railway premises as a result of train operations or } \\
\text { who are harmed by any other means (possibly } \\
\text { scaled as "per passenger km") - this would include } \\
\text { falls on station platforms, accidents due to } \\
\text { passenger behaviour etc }\end{array}$ \\
\hline $\begin{array}{l}\text { Risk of death or serious } \\
\text { injury to railway } \\
\text { employees. } \\
\text { It may be effective to sep } \\
\text { may be the correct scalin } \\
\text { correct for on-board wor }\end{array}$ & $\begin{array}{l}\text { Total number of deaths and of serious injuries (per } \\
\text { track } \mathrm{km} \text { ); includes staff employed by contractors }\end{array}$ \\
\hline $\begin{array}{l}\text { Risk of death or serious } \\
\text { injury to third parties } \\
\text { (innocent or } \\
\text { illegitimately present) }\end{array}$ & $\begin{array}{l}\text { Total number of deaths and of injuries (per train } \\
\mathrm{km} \text { ); includes harm to persons correctly using level } \\
\text { crossings or living near the railway. This should } \\
\text { also include trespassers and persons using level } \\
\text { crossings incorrectly and contributing to the cause } \\
\text { of the accident }\end{array}$ \\
\hline \multicolumn{2}{|c|}{$\begin{array}{l}\text { In adopting these positions, it should be noted that in practice it is often not } \\
\text { possible to identify innocent and culpable third parties. } \\
\text { Care will need to be exercised by Member State to ensure a satisfactory way } \\
\text { is developed for determining into which category each victim should be } \\
\text { placed. }\end{array}$} \\
\hline
\end{tabular}

This risk is expressed as a collective risk and not an individual risk, and is meant to essentially include risks of catastrophic accidents involving people and the environment, for example the release of dangerous goods. Since these events ought to be extremely rare, it is considered that a factor for scaling would not be necessary, therefore a unit per year for each country is suggested. It is suggested to use Global CSTs and Specific CSTs related to the identified parts of the railway system. One or more corresponding Common Safety Indicators (CSIs) can measure the level to be achieved by Member Sates. 
General Indicators: measure the overall level of safety of the railway within a Member State (Table 1).

Specific Indicators: measure the effectiveness of the SMS of individual companies (RU \& IM). The safety level of the whole system must be reached by different parts of the system. Firstly the performance of the whole system and the effectiveness of Safety Management System should be measured.

Societal risk proposed by SAMNET should contain (Tordai [13]):

- Risks that affect society as a whole, such as environmental harm. This is in addition to the total risk of harm to groups such as individual passengers, staff, level crossing users and unauthorised persons,

- Risks to persons living near the railway (railway neighbours),

- Risks of collective accidents, that is of accidents causing multiple fatalities,

- Intermodal effects, for example the fact that passengers will transfer to road because they perceive the railway to be unsafe,

- The risk that the public will lose trust in the institutions of the State.

\subsection{CSM (Common Safety Methods)}

According to the European Safety Directive (Directive [8]) the Common Safety Methods (CSMs) are the methods to be developed to assess whether safety targets and other safety requirements are met. Typical CSMs shall comprise methods for:

- Risk evaluation and assessment;

- Assessing conformity with requirements in safety certificates and safety authorisations (issued in accordance with the Articles of the directive), and;

- Checking that the structural subsystems of the trans-European high-speed and conventional rail systems are operated and maintained in accordance with the relevant essential requirements (as far as they are not yet covered by TSIs).

This section focuses on the CSM for Risk Evaluation and Assessment, as this is both a priority in the Safety Directive and the area where most previous activity has been focussed. A common framework for application of safety methods can consists of:

- System Definition

- Identification of Hazards

- $\quad$ Risk Analysis

- $\quad$ Risk Evaluation

- $\quad$ Risk Reduction

- Risk Control

- $\quad$ Risk Monitoring

- $\quad$ Risk evaluation and assessment

The urgent priority in the Safety Directive (Directive [8]) is for the development of a CSM to address risk evaluation and assessment. A literal interpretation of the Safety Directive implies that the CSM for risk evaluation and assessment 
includes just a method for assessing the risk associated with the railway system, and comparing those against a set of defined risk criteria (i.e. System Definition, Identification of Hazards, Risk Analysis and Risk Evaluation). 'Risk Evaluation and Assessment' must support the development of an organisation's safety requirements and the procedures that comprise the SMS. The generic CSM framework for assessing conformity with the typical elements that may be required when safety certificates and safety authorisations are issued in accordance with Articles 10 and 11 of the directive, consist of, amongst others, Risk Reduction, Risk Control and Risk Monitoring.

\subsubsection{CSMs for risk evaluation and assessment}

There is an inherent difficulty in allowing a variety of tools and techniques to be applied for risk analysis and assessment (Bearfield et al. [1]). It is therefore important to establish the degree of commonality that is actually required between member states in the application of the CSMs. There are three key principles:

- Commonality of the System Definition. The System Definition activity provides the scope of all subsequent risk identification, analysis and management activity. The requirement should be that any systems breakdown is consistent with the interoperability directives Product Breakdown Structure or the AEIF Functional Breakdown Structure (at least at the highest level of abstraction).

- Commonality of Conceptual Model used to undertake Risk Assessment. The bow-tie concept (Figure 3 ) is the generally accepted conceptual model used to structure risk analysis and assessment. There are various tools and techniques that can be used to elaborate this conceptual model and undertake more detailed risk analysis depending on the depth of analysis required and the nature of the accident and its various causes.

- Commonality of Base Units of Risk. 'Risk' is accepted to be the product of the probability of occurrence of an accident and the severity of that accident. However there are various and different approaches adopted across each member state for quantifying risk and a number of units of risk used. If the base units for risk are standardised then the results of any analysis should ultimately be comparable.

Initial use of the techniques indicates that the "Eurosig" scenarios provide a good basis for analysis.

The 'bow-tie' model is not a tool or technique for risk analysis. It represents the underlying mental model used by most safety engineers to undertake risk analysis. The majority of risk analysis tools and techniques develop and formalise this representation in various ways.

3.1.1.1 Risk evaluation Once the risks associated with the various hazards have been calculated it is necessary to evaluate their acceptability. The tolerability of calculated risks should be evaluated against the CSTs derived for the project. The total number of deaths and injuries should be weighted against some agreed criteria such as 'equivalent fatalities'. The 'equivalent fatalities' 
would represent an aggregation of 'fatalities' and 'major' injuries according to a ratio yet to be decided (e.g. 1 fatality $=10$ major injuries $=1$ equivalent fatality). The current proposal is that minor injuries would not be included in the measures, as they tend to indicate risk associated with low severity accidents.

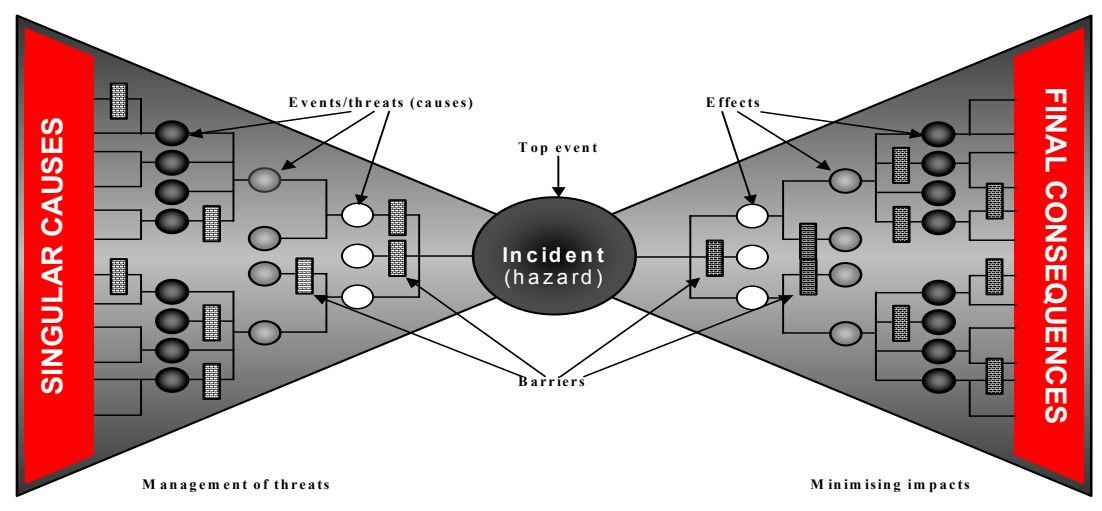

Figure 3: Bow-tie model.

\subsubsection{CSMs for meeting safety requirements}

The CSMs for meeting safety requirements (Directive [8]) are related to:

- Defined in the safety certificate of each RU

- Defined in the safety authorisation for each IM

- Derived for structural sub-systems not completely covered by TSIs

CSMs are required for ensuring that the various safety requirements put in place by an organisation are routinely and continually met by the organisation. This CSM should comprise of the risk reduction, risk control and risk monitoring stages of the risk assessment process.

3.3.2.1 Risk reduction The possible approaches to risk reduction are:

- Revision of the technical system design

- Modification of operational procedures

- Changes to staffing arrangements

- $\quad$ Training of personnel to cope with the hazard

These risk reduction approaches essentially describe revisions that an organisation can easily make to its safety requirements.

3.3.2.2 Risk Control and Monitoring Risk Control and Monitoring is about how an organisation understands the practical effectiveness of the safety requirements. The organisation must monitor all of its barriers to ensure that failures or weaknesses in the barriers are identified and rectified before an accident actually occurs. The barriers in an organisation are its safety requirements. Each different type of barrier should be monitored using a different process. For example, where the safety requirements are operational 
procedures they can be controlled and monitored using safety inspections, and auditing. Where the safety requirements are functional system requirements they can be monitored by inspection or they may also have diagnostic functions which aid in understanding where safety requirements are no longer being met or are ineffective. A common tool to assist risk reduction and control is the use of a Hazard Log. This involves recording all identified hazards and actions that mitigate risk in the Hazard Log.

\section{Conclusion}

The basic element to develop the common safety targets and methods is the establishment and the agreement on common definition of railway system. The approach proposed in this paper allows the definition of global safety targets according to the safety directive and the development of specific targets related to specific parts of the system based on the functional architecture of railway system developed by AEIF “Association Européenne pour l'Interopérabilité Ferroviaire". The purpose of Common Safety Indicators "CSIs" is to monitor European railway safety performance. It is essential that an agreed set of common safety indicators should be used to ensure that measured safety performance of different organisations are comparable and are related to Common Safety Targets "CSTs". In this paper, we suggest the definition of global safety indicators in relation with the global safety targets prescribed by the safety directive. The specific indicators can be used for critical events and not be based on accidents (this is covered by Global Indicators). The common safety methods can be based on existing tools and techniques used to develop a safe railway system. The Common Safety Methods "CSMs" are required for ensuring that the various safety requirements put in place by an organisation are routinely and continually met by the organisation. The CSM process should be based on existing known techniques (e.g. CENELEC 50126).

\section{References}

[1] Bearfield, G et al (2005), D1.3.2: "Common Safety Methods Position Paper", www.samnet.info, 11/07/2005.

[2] Bearfield, G, S. Mitra and E.M. El Koursi (2004). Guidelines for Safety Management System, D2.2.2/V3.0, www.samnet.info, May 2004.

[3] Cassir, C et al (2005), D1.3.3: "Specific CSTs report Case study", www.samnet.info, 10/06/2005.

[4] Chatel, V, E.M. El Koursi, C. Felliot, U. Huismann (2002) "Functional analysis of the sub-system of energy and infrastructure of conventional rail", SMC, 2002, Hammamet, Tunisie.

[5] El Koursi E.M, S. Fletcher, L. Tordai, J. Rodriguez (2006-a) “ SAMNET synthesis report - safety and interoperability, www.samnet.info, February $15,2006$. 
[6] El Koursi, E.M, N. Duquenne (2006-b), "Assessment of the Safety management system in railway sectors", WCRR2006, Montréal, Canada, 4-8 June 2006.

[7] El Koursi E.M. and L. Tordai (2003), "SAMNET: Safety management and interoperability thematic network in railway systems", WCRR2003, Edinburgh pp: 198-202, (2003).

[8] Directive 2004/49/EC (2004) on safety on the Community's railways and amending Council Directive $95 / 18 / \mathrm{EC}$ on the licensing of railways undertakings and Directive 2001/14/EC on the allocation of railway infrastructure capacity and the levying of charges for the use of railway infrastructure and safety certification (Railway Safety Directive), L164 p44-113, 29 April 2004, Official Journal of the European Union.

[9] Directive 2001/16/EC (2001) of the European Parliament and of the Council on the interoperability of the trans-European conventional rail system, Commission of the European Communities, Brussels, 19 March 2001.

[10] Directive 96/48/EC (1996) on the interoperability of the trans-European high speed rail system, Commission of the European Communities, Brussels, 23 July 1996.

[11] Gigantino, A (2002) 'Report on the Representative Architecture', AEIF, 19 September 2002.

[12] Mihm, P et al (2004), D2.4.0:“Acceptable Risk Level”, www.samnet.info, June 2004.

[13] Tordai, L "Common Safety Indicators and Common Safety Targets of European Railways”, WCRR2006, Montréal, Canada, 4-8 June 2006. 